2. McDowell F. The Source book of Plastic Surgery. Williams and Wilkins Co: Baltimore; 1977. p. 65-85.

3. Hoernle AF. Studies in the Medicine of Ancient India. Part 1. Osteology or the Bones of the Human Body. Clarendon Press: Oxford; 1907. p. 109.

4. Johnson-Saint P. An Outline of the History of Medicine in India. Indian Med Rec 1929;49:289.

5. Wise TA. Commentary on the Hindu System of Medicine. Thacker: Calcutta; 1845. p. 1.

\section{Role of stem cells in Plastic Surgery}

Dear Sir,

Stem cells have created a lot of interest and attention over the past few years, mostly for their potential in treating variety of medical and surgical conditions.

Recently, stem cell research has started exploring the potential use of a patient's own stem cells for tissue replacement and rejuvenation in plastic surgery.

Presently, there is a lot of concern about the currently available breast implants, which are marred by the tendency to form contracture, propensity to rupture, leak and possible interference with breast cancer detection. The materials being used in facial plastic surgery too, are less than ideal. The various allogenic materials used in facial cosmetic surgery tends to lose its size and shape over time. Even conventional soft tissue reconstruction following cancer or trauma surgeries can lose 40-60 percent of their volume over time.

The new technique of tissue engineering is expected to revolutionize various aspects in reconstructive and aesthetic surgery. Reconstructive surgery could greatly benefit from stem-cell generated natural tissue that does not shrink or lose its shape. ${ }^{[1]}$ Whereever large areas need reconstruction, like in head and neck cancers or breast cancers; it will be possible with stem cell technique to take stem cells from the patient, grow them in vitro, and subsequently use this autogenous tissue for reconstruction. ${ }^{[2]}$ Stem cells also offer the possibility of prefabrication of flaps, ${ }^{[3]}$ reconstruction of auricular framework, articular condyle, vascularized bone flaps,cranial bone defects and renewable source of replacement cells and tissues to cover raw areas following massive burns. ${ }^{[4]}$ At present, reconstruction often require surgery to take tissue from another location of a patient's body. The stem-cell approach might eliminate the need for the additional surgery

The advantage of a stem cell-based method in aesthetic surgery is that the implant from stem cells have the potential to provide a safer alternative to allogenic implants, and when used for wrinkle removal and breast augmentation, the implants will retain their size and shape better and longer than any other allogenic implant. ${ }^{[1]}$

We still have a long way to go and more, longer term studies will be needed as many questions remain unanswered. However, the present approach represents a giant leap in tissue engineering technology and it seems that the time is not far when the stem cell-derived tissue would offer a better way forward for both reconstructive and aesthetic surgery.

Sanjay Saraf

Department of Plastic Surgery, NMC Specialty Hospital, Dubai, UAE. E-mail:drsaraf@hotmail.com

\section{REFERENCES}

1. Alhadlaq A, Tang M, Mao JJ. Engineered adipose tissue from human mesenchymal stem cells maintains predefined shape and dimension: Implications in soft tissue tissue augmentation and reconstruction. Tissue Eng 2005;11:556-66.

2. Patrick Jr CW. Adipose tissue engineering: The future of breast and soft tissue reconstruction following tumor resection. Semin Surg Oncol 2000;19:302-11.

3. Casabona, Martin I, Muraglia A, Berrino P, Santi P, Cancedda R, et al. Prefabricated Engineered Bone Flaps: An Experimental Model of Tissue Reconstruction in Plastic Surgery. Plast Reconstr Surg 1998;101:577-81.

4. Pellegrini G, Ranno R, Stracuzzi G, Bondanza S, Guerra L, Zambruno, et al. The control of epidermal stem cells (holoclones) in the treatment of massive full-thickness burns with autologous keratinocytes cultured on fibrin1. Transplantation 1999;68:86879 .

\section{Response to "Anatomy of an internet consultation"}

Dear Sir,

My heartfelt gratitude to the association and to you for keeping me on your mailing list. Though I retired 10 years ago, I try to keep up with the new innovations and ideas by reading journals. I specially enjoy the Indian 